\title{
Adaptation of an Early Design Stage Tool for Assessment of Sustainable Energy Systems (SES) in Large UAE Buildings
}

\author{
K. Shanks * \\ School of Energy, Geoscience, Infrastructure and Society (EGIS), Heriot-Watt University, Dubai, U.A.E.
}

\begin{abstract}
The paper outlines a new design tool for the assessment of sustainable energy systems (SES) for large buildings that is being adapted for the UAE building stock and climate context. The structure and underlying framework is discussed for SES and building types appropriate to the UAE. The mapping of the various levels of input and output of the tool to a typical design development process are described and initial characterization of some components are presented.
\end{abstract}

\section{Introduction}

Sustainable energy systems (SES) offer ways of sourcing energy to meet building energy demands that significantly mitigate energy related $\mathrm{CO}_{2}$ and other GHG emissions. SES achieve this by either being driven by a renewable energy source or having enhanced energy efficiency due to making use of waste energy streams. SES can also be classified as low or zero carbon technologies (LZCT) which more precisely reflects their key benefit of lower emissions generated in providing the types of energy needed to meet building end-use energy demands. Increased adoption of these SES in the building stock will lead to lower emissions in meeting energy needs.

The integration of SES in a building typically has different implications for design than more conventional energy systems. These vary depending on the specific type of SES but generally include plant room space needs, greater use of roof areas or particular elevations, use of adjacent external space, use of ground beneath a building and the type of building services systems, e.g. generation of cooling; air-conditioning and domestic hot water. They can also have different impacts on building management needs and operating costs. Due to these wide ranging implications and associated factors affecting optimal SES integration it is valuable to consider and evaluate impacts of different systems from the earliest stages of building design. This paper outlines an early design stage tool that assesses these implications of adopting SES in large buildings, i.e. $>1,000 \mathrm{~m} 2$ conditioned floor area. As part of a current project to adapt such a tool to the UAE context, the

${ }^{*}$ Corresponding author

E-mail: K.Shanks@hw.ac.uk

(C) 2015 International Association for Sharing Knowledge and Sustainability

DOI: $10.5383 /$ swes.7.02.007 original tool was developed under funding from the Sustainable Energy Authority of Ireland [1], some of the details reported here represent adaptations relevant to the UAE building stock and climatic context. The successful implementation of SES in new building development projects involves consideration of integration issues and factors that affect performance from the earliest design stages through to detailed design. In the earliest design stage when a design concept is being developed identification of key issues affecting the suitability of SES for a project and the types of impacts these have on other building design aspects are needed quickly. As design development moves onto the initial detailed design stage, when costs are typically being set, the costs and benefits of SES need to be evaluated. This evaluation is mainly site or project specific. Therefore through early design stages of a project the type of information needed to inform decisions evolves from being qualitative to being more quantifiable.

\section{Sustainable Energy Systems (SES) for Large Buildings}

SES essentially provide a more sustainable way of meeting one or more of the forms of energy needs in a building or group of buildings and can be grouped into the following generic categories: 


\author{
- Cooling \\ - Power (electricity) \\ - $\quad$ Combined (thermal and electricity) \\ - Heating
}

Within each of these categories SES deliver a particular form of energy from a natural resource, i.e. solar; wind; low grade thermal exchange, or from a renewable fuel, e.g. biomass; biogas, or from a local waste heat stream. The suitability and performance of SES therefore are generally a function of the availability of a resource or fuel and matching the availability profile of this with the end-use energy demand profile. The former is driven by a project and sites context and the latter by building function, usage pattern and energy performance.

The SES most appropriate for buildings in the UAE, and therefore included in the adapted tool, include:

$\begin{array}{ll}\text { - } & \text { Absorption cooling } \\ \text { - } & \text { Solar assisted } \\ \text { - } & \text { Gas fuelled } \\ \text { - } & \text { Ground coupled cooling } \\ \text { - } & \text { District or block cooling } \\ \text { - } & \text { Solar photovoltaic } \\ \text { - } & \text { Small to medium scale wind } \\ \text { - } & \text { Combined, Cooling, Heat \& Power (CCHP) } \\ \text { - } & \text { Biogas fuelled } \\ \text { - } & \text { Biomass fuelled } \\ \text { - } & \text { Gas fuelled } \\ \text { - } & \text { Solar water heating }\end{array}$

\section{Stages of Building Design Development}

As a building design develops, the type and nature of information available changes, typically evolving from qualitative to quantitative. In the earliest stage or design briefing only a limited amount of information is available, such as the type of building or its generic type of use(s), e.g. hospital, residential etc. and the location and size of the site. As design develops the information available becomes more detailed and thereby has an associated impact on the level of detail needed to make design decisions.

Some existing methodological frameworks are available and in use for evaluation of SES at early planning and design stages, e.g. London Renewables Toolkit [2]. There is also a wide range of more detailed tools available for evaluating the costs and benefits of many types of SES. These sets of tools are most appropriate for particular stages in design development, e.g. early design options only or later detailed design providing engineering design type output. They typically require either qualitative or quantitative information inputs from the user. Most qualitative based tools do not provide flexibility to evaluate the impact of SES technical options, e.g. differences in rated output of different photovoltaic cell options. Conversely most quantitative based tools need technical inputs and therefore can only be used when a particular amount of design detail has been developed.
Mapping the type of information, both available and needed, to inform decision making at different stages in a typical design development process illustrates the value of a tool that combines qualitative and quantitative assessment techniques. The typical stages of building design development are:

- $\quad$ Project inception or brief

- Preliminary proposals or design options

- $\quad$ Scheme design

- $\quad$ Initial detailed design

- $\quad$ Detailed design

To address the opportunities for optimal application of SES at earlier design stages, a framework has been developed to characterize implications at the preliminary proposals, scheme design and initial detailed design stages.

\subsection{Stage 1 Preliminary Proposals}

At the preliminary proposals stage the objectives and characteristics of the building project are limited and subject to change. Only general objectives or plans are known. Even at this early stage some of these general project objectives have implications for the suitability of SES which in turn have implications for how the building design develops. These include:

$\begin{array}{ll}\text { - } & \text { Generic Building Function(S) or Type } \\ \text { - } & \text { Approximate Floor Area } \\ \text { - } & \text { Approximate Site Size } \\ \text { - } & \text { Specific Site Location }\end{array}$

Generic building function, see Table 1 for list of UAE building types, provides an indication of the scale and temporal profile, diurnal; weekly and seasonal, of energy end use. For example, airport terminals will have a high demand for power (large retail area, office, baggage handling), plus space heating/cooling, small dispersed hot water demand; 24/7 operation with peak between $10 \mathrm{pm}-6 \mathrm{am}$. This qualitative characterization can be matched to the generic supply characteristics of typical cost effective applications of SES to indicate their suitability for a building type.

Approximate floor area, either the building as a whole or for different generic functions within a building or multiple buildings, has a direct impact on the most appropriate scale of SES. For example, the component, fuel options and cost effectiveness of some SES such as CCHP and district or block cooling are directly dependent on the scale of energy to be delivered. Similarly, approximate site size combined with floor areas gives an early indication of potential for ground coupled cooling.

Specific site location has an influence on potential constraints for SES use in terms of planning requirements, e.g. small to medium scale individual wind turbines, or the sites proximity to low grade heat sinks such as homogenous earth below the surface. However, at this stage of a project, some of these factors may be unknown. Therefore a tool that can readily draw attention to the lack of such influential information and direct 
the design team to obtaining the correct information before moving onto the next stage is valuable.

It can be seen that such early design stage objectives and general characteristics can be used to derive suitability weightings of SES in a building project. Furthermore, performing such an evaluation at the design options stage will drive collation of more specific information to further inform decisions as the design develops.

\subsection{Stage 2 Scheme Design}

At the scheme design stage, building plans are developed for submission to authorities and clients and should include representation of building massing, rooflines, multiple building organisation, orientation and general landscaping. To achieve this, the design team gains greater understanding of the site and evaluates the budget needs in terms of construction specification. This information, which can be characterised in qualitative terms, can be used to provide more accurate evaluation of the potential of SES. Some key characteristics typically available at this stage include:

- District cooling, is there a district cooling network on or adjacent to the site

- Solar access, orientation and overshadowing

- Wind resource, local turbulence and space for locating turbines

- Plantroom space

- Fuel storage space

- Biogas feedstock supply chain

- Waste heat sources

- Particular planning requirements, e.g. designated area such as special area of conservation

By collating and clarifying these site characteristics it is possible to refine the evaluation of

SES conducted at the earlier design options stage and make decisions on where to provide allowances for SES integration.

\subsection{Stage 3 Initial Detailed Design}

At the initial detailed design stage a primary objective for the design team is to select building technical and energy system options in the context of technical suitability and cost effectiveness. Although there is only general information on design and site characteristics at this stage, these decisions rely heavily on quantification of the costs and benefits of suitable options.

To estimate costs and benefits of the most suitable SES, evaluated and refined at the earlier stages, typical and best practice costs and performance parameters can be used. The key metrics representing the environmental and economic costs and benefits of any SES, at this stage of design include:

$\begin{array}{ll}\text { - } & \text { Capital cost } \\ \text { - } & \text { Annual } \mathrm{CO}_{2} \text { saved } \\ \text { - } & \text { Annual cost saving } \\ \text { - } & \text { Simple payback period } \\ \text { - } & \text { Net Present Value (NPV) }\end{array}$

\author{
- $\quad \mathrm{NPV} /$ tonne of $\mathrm{CO}_{2}$ saved \\ - Internal Rate of Return
}

Equation sets have been developed for the SES listed in Section 2.0 and include the various technology specific parameters that influence performance and cost effectiveness of best practice application. These parameters also represent some characteristics of a building's design that can be modified at this stage of the design process to optimise SES performance such as, orientation of facades or provision of larger fuel storage areas etc.

This simplified estimation of SES cost benefit metrics at this stage of design development enables inter-technology comparison and directly informs sustainable energy decision making.

\section{SES Suitability and Estimated Performance}

Using a similar framework as the characterization of building project objectives and the site outlined in section 3.0 the implications and typical cost effective application of each SES can be characterized.

\subsection{Stage 1 Preliminary Proposals}

With the limited information available for a building project and site outlined in 3.1 above it is still possible to determine the suitability of the different SES.

Where building function(s) provides an indication of the scale and temporal profile of energy end use demands of a building, the suitability of an SES is related to matching this demand scale and profile with that of the energy source. Adopting a three tier representation of SES suitability, i.e. highly suitable; likely to be suitable and not likely to be suitable, it is possible to map the suitability of technologies to building functions. For example, solar water heating's degree of suitability can be qualitatively defined as:

- Highly suitable where there is high year round or summer hot water demand, e.g. in a hotel

- Likely to be suitable where there is reasonable hot water demand, e.g. in a further/higher education building

- Not likely to be suitable where there is little or no hot water demand, e.g. in a telephone exchange or server farm

Similarly, suitability can be further defined in terms of other general building and site characteristics. For example, the suitability of absorption cooling can be qualitatively defined as:

- Highly suitable in large building types with access to waste or surplus heat, e.g. a hospital

- $\quad$ Likely to be suitable in medium sized building types with access to waste or surplus heat, e.g. a hotel

- $\quad$ Not likely to be suitable in small building types with low or highly unpredictable cooling demands, e.g. in nursing residential homes and hostels 


\subsection{Stage 2 Scheme Design}

The degree of suitability of an SES can be further refined to address the key characteristics outlined in section 3.2 above. This refinement of qualitative assessment enables provides the design team with further output as the overall shape, form and massing of the building design develops.

Taking the example of solar water heating the most influential or main constraining characteristics known at the outline design stage, are, solar access and planning requirements. In terms of solar access, if a buildings pitched roof is or can be oriented between south-east and southwest then suitability of solar water heating is unaffected. However, if not it is only likely to be a suitable application. Similarly, if the roof area where solar collectors are to be installed is free from overshadowing from other buildings or obstructions then suitability is unaffected. Whereas, if there is some overshadowing performance will be affected resulting in it only being "likely to be suitable". In terms of planning requirements there may be specific requirements for roof lines that restrict locating collectors on the roof. This would result in solar water heating being at best "likely to be suitable" and at worst "not suitable".

\subsection{Stage 3 Initial Detailed Design}

For each SES there are a range of both common technology specific factors that affect estimation of their costs and benefits. Common factors include:

- Retail price of electricity, gas, oil and liquid petroleum gas (LPG)

- $\mathrm{CO}_{2}$ emission factors for energy and fuels being offset, i.e. electricity, gas, oil and LPG

\section{- Financial discount rate}

Equation sets have been developed to calculate the amount of end use energy supplied by each SES based on a selected range of technology specific performance factors, e.g. parasitic gas consumption factor for anaerobic digesters. These figures are used to quantify the amount, cost and $\mathrm{CO}_{2}$ emissions of the conventional or carbon based fuel that would be offset by using the particular SES.

These calculations draw on generic building type annual energy demand benchmarks for the following end uses:

- $\quad$ Delivered space cooling

- Delivered hot water

- $\quad$ Space cooling

- $\quad$ Fans and pumps

- $\quad$ Lighting

- $\quad$ Other electric (e.g. small power, lifts, etc.)

\section{Building Types and Functions}

As the assessment tool relies on matching qualitative and quantitative characteristics of a large number of building types with those of appropriate SES, the scale and temporal profiles of all main end-use energy demands in buildings typical in the UAE are required, for typical building types see Table 1 below.
Table 1 - Typical UAE Building Types

\begin{tabular}{|l|l|}
\hline Building type & \\
\hline Civic - Courts & Industrial - Process buildings \\
Civic - Police HQ and Control & Industrial - Warehouse and storage \\
Centres & buildings \\
Civic - Libraries & Industrial - Workshops \\
Civic - Mosques & Office - general \\
Communications - Telephone & Office - cellular air conditioned \\
exchanges & Office - open plan air conditioned or \\
mixed mode & Office - prestige office or HQ office \\
Education - Academic research & \\
facilities & Retail - General (small malls) \\
Education - Academic & Retail - General (large malls) \\
teaching/Conference facilities & Retail - Small retail units \\
Education - Further/Higher Education & Retail - Supermarkets \\
Universities/Institutions & Retail - Warehouse (e.g. hardware, \\
Education - High Schools & furniture etc.) \\
Education - Nurseries & Sports - Arenas, sports grounds \\
Emergency Services - Fire and & Sports - Dry sports centre (including \\
Ambulance Stations & fitness suite) \\
Entertainment - Cinemas (multiplex) & Sports - Special function \\
Entertainment - Museums and & \\
Galleries & Transport - Airport terminals \\
Entertainment - Theatres and & Transport - Tram Station, Seaport \\
Auditoria & Terminal \\
Healthcare - Community centres & \\
Healthcare - Hospitals & \\
Hospitality - Fast food outlets & \\
Hospitality- Hotels (with/without & \\
spa) & \\
Hospitality- Clubs & \\
Hospitality- Restaurants & \\
Housing - low rise, low density \\
(Villas)
\end{tabular}

Benchmark data representing standard and best practice building energy performance is under development for each of these UAE building types. Due to a lack of long term data these end-use energy benchmarks are being developed based on a combination of empirical studies, reported in the literature, international benchmarks adjusted for the UAE climate and dynamic modelling based on national building regulations and standards.

\section{Conclusion}

The project, site and building type factors having an impact on cost effective application varies for each type of SES and decisions related to these occur early in the design development of a building project.

This paper has outlined an assessment tool for identifying and evaluating these to inform decision making in the earliest three stages of a typical design development process. As a building design, and the associated information available about the project and site evolve, the type of output needed in relation to decisions on SES options also evolves from a qualitative to a 
quantitative format. The tool described in this paper provides such a multi-stage evaluation of SES options.

The tool under development, which is based on previous work but adapted for the UAE, has been designed to give useful output with minimal input requirements whilst also being able to evaluate economic and environmental performance impacts of some key technology specific, building integration and component options. This tool can be used as both an educational resource and design tool to steer early design development in the direction of cost effective application of SES in new buildings as a precursor to detailed engineering design optimisation. The simplicity and flexibility of the developed framework ensures its value can be enhanced by use of building specific energy end use demand data and SES manufacturers, cost and technical specification data. Further work will result in this tool being made available for use in the UAE.

\section{References}

[1] Shanks, K., 2007, Early design stage evaluation tool for sustainable energy systems in large new buildings, Portugal SB07. Sustainable Construction, Materials and Practices Challenge of the Industry for the New Millennium

[2] Integrating renewable energy into new developments: Toolkit for planners, developers and consultants. Greater London Authority, UK, ISBN 1 $852616601,(2004)$ 